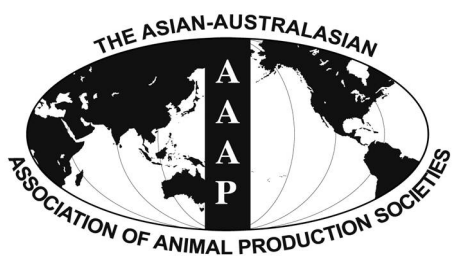

Open Access

Asian Australas. J. Anim. Sci.

Vol. 28, No. 11 : 1662-1668 November 2015

http://dx.doi.org/10.5713/ajas.15.0330

Www.ajas.info

pISSN 1011-2367 elSSN 1976-5517

\title{
Effect of Suckling Systems on Serum Oxytocin and Cortisol Concentrations and Behavior to a Novel Object in Beef Calves
}

\author{
Siyu Chen, Shigefumi Tanaka, Shin-ichiro Ogura, Sanggun $\operatorname{Roh}^{1}$, and Shusuke Sato* \\ Lab of Land Ecology, Graduate School of Agricultural Science, Tohoku University, Miyagi 989-6711, Japan
}

\begin{abstract}
We investigated differences between effects of natural- and bucket-suckling methods on basal serum oxytocin (OT) and cortisol concentrations, and the effect of OT concentration on affiliative and investigative behavior of calves to a novel object. Ten Japanese Black calves, balanced with birth order, were allocated evenly to natural-suckling (NS) and bucket suckling (BS) groups. Blood samples were collected at the ages of 1 and 2 months (1 week after weaning) calves, and serum OT and cortisol concentrations were measured using enzyme-linked immunosorbent assay and enzymeimmunoassay tests, respectively. Each calf at the age of 2 months ( 2 weeks after weaning) was released into an open-field with a calf decoy, and its investigative and affiliative behaviors were recorded for 20 minutes. In 1-month-old calves, the basal serum OT concentration $(25.5 \pm 4.9$ [mean \pm standard deviation, $\mathrm{pg} / \mathrm{mL}$ ] $)$ of NS was significantly higher than that of BS $(16.9 \pm 6.7)(\mathrm{p}<0.05)$, whereas the basal cortisol concentration $(5.8 \pm 2.5$ [mean \pm standard deviation, $\mathrm{ng} / \mathrm{mL}])$ of NS was significantly lower than that in BS $(10.0 \pm 2.8)(\mathrm{p}<0.05)$. Additionally, a negative correlation was noted between serum OT and cortisol concentrations in 1 -month-old calves $(\mathrm{p}=0.06)$. Further, the higher serum OT concentration the calves had at 1 month old, the more investigative the calves were at 2 months old but not affiliative in the open-field with a calf decoy. Thus, we concluded that the natural suckling method from a dam elevates the basal serum OT concentration in calves, and high serum OT concentrations induce investigative behavior and attenuate cortisol concentrations. (Key Words: Oxytocin, Cortisol, Natural Suckling, Investigative Behavior, Calf, Stress)
\end{abstract}

\section{INTRODUCTION}

In intensive cattle production systems, calves are separated from their dams immediately, or a few hours, after birth. For effective animal management, calves are initially maintained in individual pens preventing them from sucking one another, to simplify feeding and disease inspection routines (Grøndahl et al., 2007). However, it is recognized that bucket suckling causes welfare problems such as leading to frustration of suckling motivation and then formation of hair balls in the rumen and wounds in the inter-sucked parts of calves. Das et al. (2000) reported that inter-sucking is principally found in young bucket-fed

\footnotetext{
* Corresponding Author: Shusuke Sato. Tel: +81-229-84-7382, Fax:+81-229-84-7382, E-mail: shusato@bios.tohoku.ac.jp

${ }^{1}$ Lab of Animal Physiology, Graduate School of Agricultural Science, Tohoku University, Miyagi 981-8555, Japan.

Submitted Apr. 17, 2015; Revised May 20, 2015; Accepted Jun. 3, 2015
}

calves separated from their dams. In Japanese Black cattle, it was reported that artificial suckling might suppress suckling behavior, contributing to the onset of stereotypies such as tongue playing (Sato et al., 1994). Seo et al. (1998) also showed that tongue playing was more frequent among artificially reared calves housed in individual pens than in groups. In rats, maternal deprivation results in a significant decrease in plasma adrenocorticotrophic hormone concentration and increase in plasma corticosterone compared to that in non-deprived rats (Suárez et al., 2001). Hernández et al. (2006) reported that artificially reared calves also had a significantly higher level of serum cortisol concentration than in those suckling from their mothers. In addition, it was suggested that individually housed calves are more fearful than group-housed calves, when introduced to new social situations or when isolated in a novel arena (Jensen et al., 1997). The above studies indicate that solitary bucket suckling may result in negative emotions in animals.

However, it was reported that calves housed with dams 
during the colostrum period were more social with unfamiliar heifers (Krohn et al., 1999), and sheep and lambs suckling immediately after birth showed preferential relationships with the ewes (Nowak et al., 1997). Further, in Krohn's (2001) review, he concluded that more than artificial rearing systems, natural suckling systems where calves are nursed by their dams and have social contact with other calves and cows are more beneficial to calf welfare such as a positive effect on the daily gain and vitality of the calf. Oxytocin (OT) has recently received attention as a positive indicator of pleasure of livestock, one of the most important aspects of animal welfare (Broom and Fraser, 2007). It was reported that OT injections after a stress test induced normalization of the emotional state in rats (Svanidze et al., 2012). In humans, OT reduced activation of the amygdala, a central component of fear neurocircuity (Kirsch et al., 2005). Odendaal and Meintjes (2003) revealed that $\beta$-endorphin, OT, and dopamine increased in humans and dogs after positive interspecies interactions. Additionally, it was reported that OT regulated affiliative behavior in prairie voles (Rose et al., 2009). Therefore, we speculated that natural suckling is a pleasure event for the calf which induces serum OT concentrations, and then elevates the basal serum OT concentration during the longterm natural suckling period, which might affect affiliative and investigative calf behaviors in the calf.

Accordingly, the aim of the present study was to investigate the differences between the long-term effect of natural and bucket suckling systems on basal OT and cortisol concentrations in serum, and the effect of OT concentrations on affiliative and investigative behaviors to a novel object in calves.

\section{MATERIALS AND METHODS}

This study was carried out at the Field Science Center, Graduate School of Agricultural Science, Tohoku University, Japan. Ten Japanese Black male calves (born from May 2012 to July 2012), balanced with birth order, were assigned into a natural-suckling group $(\mathrm{NS}, \mathrm{n}=5)$ and a bucket-suckling group (BS, $\mathrm{n}=5$ ). We obtained ethical approval for this experiment by the president of Tohoku University, Sendai, Japan (approval number: 2012 agriculture animal-65).

\section{Animal management of natural- and bucket-suckling calves}

In NS, the calves were raised with their dams after birth and were allowed to suckle freely in a nursing barn. The barn consisted of an indoor lying area $(16 \mathrm{~m} \times 10 \mathrm{~m})$ covered with straw and equipped with a feeder $(40 \mathrm{~cm} \times 10 \mathrm{~m})$. Hay and water were constantly available, and a small amount of concentrates was fed to the cows. Animals in the barn were approximately five dam-offspring pairs, including the experimental pairs. After 1 month old, calves were fed hay and starter placed in the creep area. Water was provided $a d$ libitum.

In BS, calves were removed from their dams the day after the birth, hence they were fed colostrum in the day of birth. As there were no health problems to calves after separation from their dams, they seemed to receive colostrum substantially. They were raised independently in single hutches $(1 \mathrm{~m} \times 2 \mathrm{~m})$ with concrete floors covered with hay. The single hutches were set next to each other and located in a separate barn. The calves were spatially, but not visually or acoustically, isolated from each other. They were fed commercial artificial milk powder (All-in-One, Tokyo, Japan) dissolved in warm water $(300 \mathrm{~g} / 3 \mathrm{~L})$, twice daily at 08:40 and 15:40. Milk was administered through suckling buckets with nipples. The BS calves were fed hay and starter from 1 week of age, which were adjusted qualitatively for the calf to gain weight over $0.6 \mathrm{~kg} / \mathrm{d}$ according to the Japanese Feeding Standard for Beef Cattle (National Agriculture and Food Research Organization, 2008). Water was provided ad libitum.

All experimental calves were forbidden contact with humans except for the experimenter and stockperson. All calves were abruptly weaned at 2 months, and housed as a group with birth order, where the minimum number of calves was four and the maximum was six. The group pen was $30 \mathrm{~m}^{2}$ with a feed trough of $50 \mathrm{~cm} \times 4 \mathrm{~m}, 200 \mathrm{~m}$ away from the barn with the single hutches. The group pen was set in a big barn, with one side facing the wall and the other three sides surrounded by pipe fences. The floor was concrete covered with rice hull. Water and hay were provided ad libitum. The amount of concentrates was adjusted in the same way as that before weaning.

\section{Measurement of serum oxytocin and cortisol concentrations}

Serum samples were collected from the jugular vein of 1- and 2-month-old (1 week after weaning) calves at 13:30 for two successive days (average data were used for analysis). Because of the skilled technology currently available, the process averaged 1 minute for tying the rope and collecting serum samples, thereby limiting stress in the calves. To measure serum OT and cortisol concentrations, $15 \mathrm{~mL}$ of blood from each animal was collected in three 5$\mathrm{mL}$ tubes each containing $250 \mathrm{KIU}$ aprotinin. The tubes were kept on ice until centrifugation $(1,600 \times \mathrm{g}$ for 20 minutes). After centrifugation, the serum samples were stored at $-80^{\circ} \mathrm{C}$ until OT analysis, whereas the samples for the cortisol assay were maintained at $-20^{\circ} \mathrm{C}$. The serum OT concentration was measured using enzyme-linked immunosorbent assay (ELISA). Rabbit anti-OT purified IgG (G-051-01, Phoenix Pharmaceuticals, Inc., Burlingame, 
CA, USA) was diluted to $57 \mathrm{ng} / \mathrm{mL}$ in coating buffer $(0.015$ $\mathrm{M} \mathrm{Na}_{2} \mathrm{CO}_{3}$ and $0.034 \mathrm{M} \mathrm{NaHCO}_{3}$ : $\mathrm{pH}$ 9.6). Then, $100 \mu \mathrm{L}$ of rabbit anti-OT purified IgG was placed into a 96-well plate (445101, Thermo Scientific Nunc, Roskilde, Denmark). After 24-hours incubation at $4^{\circ} \mathrm{C}$, the 96 -well plate was washed with washing buffer $(0.05 \%$ Tween 80$)$ twice, and $250 \mu \mathrm{L}$ blocking buffer $\left(0.04 \mathrm{M} \mathrm{Na} 2 \mathrm{HPO}_{4}, 0.145 \mathrm{M} \mathrm{NaCl}\right.$, $0.1 \%$ bovine serum albumin [BSA]: $\mathrm{pH} 7.2$ ) was added to each well. After 2 hours at room temperature, the plate was washed with washing buffer twice. OT standards and serum samples $(100 \mu \mathrm{L})$ were added to each well. After 24 hours of incubation at $4{ }^{\circ} \mathrm{C}$, the plate was washed with washing buffer twice. Biotin-labeled OT (AnaSpec Inc., San Jose, CA, USA) was diluted to $1 \mu \mathrm{g} / \mathrm{mL}$ in assay buffer $(0.042 \mathrm{M}$ $\mathrm{Na}_{2} \mathrm{HPO}_{4}, 0.008 \mathrm{M} \mathrm{KH} \mathrm{KO}_{4}, 0.02 \mathrm{M} \mathrm{NaCl}, 0.0048 \mathrm{M}$ ethylenediaminetetraacetic acid (EDTA) $1.79 \mathrm{~g}, \quad 0.05 \%$ BSA: pH 7.5). Then, $100 \mu \mathrm{L}$ of diluted biotin-labeled OT was added to each well. After 24-hours incubation at $4^{\circ} \mathrm{C}$, the plate was washed with washing buffer twice. Streptavidin peroxidase (100 ng/well; S5512, SigmaAldrich, Burlingame, CA, USA) diluted in assay buffer were added to each well, and the plate was stored at $4^{\circ} \mathrm{C}$ for 1 hour. After that, the plate was washed with washing buffer twice, $100 \mu \mathrm{L}$ TMB Soluble Reagent (High Sensitivity 23141, ScyTek Laboratories, Inc., Logan, UT, USA) was added to each well, and the plate was stored at $37^{\circ} \mathrm{C}$ for 30 minutes. The reaction was stopped by adding $25 \mu \mathrm{L}$ of $2 \mathrm{~N}$ $\mathrm{HCl}$ to each well. The absorbency at $450 \mathrm{~nm}$ was measured directly through the bottom of the plates with an ELISA Reader (International Reagents Corporation, Kobe, Japan). All other reagents were purchased from Wako Chemical Ltd. (Osaka, Japan). The cortisol concentration was measured using an EIA kit by supporting of a company (Kainos Laboratories, Tokyo, Japan).

\section{Reaction to the novel object in the open-field arena}

The experimental calves were released individually into an open-field arena for 20 minutes at the age of about 2 months ( 2 weeks after weaning). The open-field arena (4 $\mathrm{m} \times 6 \mathrm{~m})$ with concrete floor was fenced with plywood panels $1.8 \mathrm{~m}$ high to prevent calves from seeing the surroundings. A novel decoy of a Holstein calf made in Denmark (height, $75 \mathrm{~cm}$; length, $100 \mathrm{~cm}$; and width, $40 \mathrm{~cm}$ ) in a net cage (height, $90 \mathrm{~cm}$; length, $120 \mathrm{~cm}$; and width, 60 $\mathrm{cm}$ ) was placed in the middle of the arena next to the inside wall, which was clearly visible but could not be directly accessed by the experimental calves. Two cameras (Sony DCR-SR 220, Sony, Tokyo, Japan) were installed on the wall before initiating the test to record calf behavior. The calves were released individually into the open-field arena and their behaviors were recorded for 20 minutes by the continuous sampling. Urine and feces excreted during the experiment were cleaned after each 20 -minutes observation.
Duration of contact with the net cage containing the decoy (s), duration of staying near the decoy ( $s$; half of the calf's body being within a $1-\mathrm{m}$ range of the cage), the bouts of approaches to the decoy, the bouts of explorations in the arena (sniffing and listening), and the number of selfgrooming behaviors were recorded.

\section{Statistical analysis}

A t-test was used to compare the means of serum OT and cortisol concentrations between NS and BS in 1- and 2month-old calves. To clarify the effects of the serum OT concentration and the rearing system (NS and BS), a general linear model with the following equation was used: $\mathrm{Y}=\beta_{1} \mathrm{X}_{1}+\beta_{2} \mathrm{X}_{2}+\mathrm{E}$, where $\mathrm{Y}$ is behavior data, $\mathrm{X}_{1}$ is the OT concentration variable, $X_{2}$ is the suckling-system variable, $\beta_{1}$ and $\beta_{2}$ are slopes, and $E$ is the error. All the data were analyzed using SYSTAT 13 statistical software (Systat Software, Inc., San Jose, CA, USA). Regression coefficients were calculated to examine the relationship between the serum OT and cortisol concentrations. All values with $p \leq 0.05$ were regarded as statistically significant and those with $\mathrm{p}<0.1$ were considered to show a significant tendency.

\section{RESULTS}

\section{Effects of the suckling system on serum oxytocin concentration}

Serum OT concentrations of NS calves were 25.5 \pm 4.9 and 21.2 \pm 2.5 (mean \pm standard deviation [SD], $\mathrm{pg} / \mathrm{mL}$ ), respectively, at the age of 1 month and 2 months (1 week weaning), while those of BS calves were $16.9 \pm 6.7$ and $22.4 \pm 2.6$, respectively. At the age of 1 month, the mean serum OT concentration of NS calves was significantly higher than that of BS calves $(p=0.05)$, whereas there was no difference between the two experimental groups of calves at the age of 2 months (Figure 1).

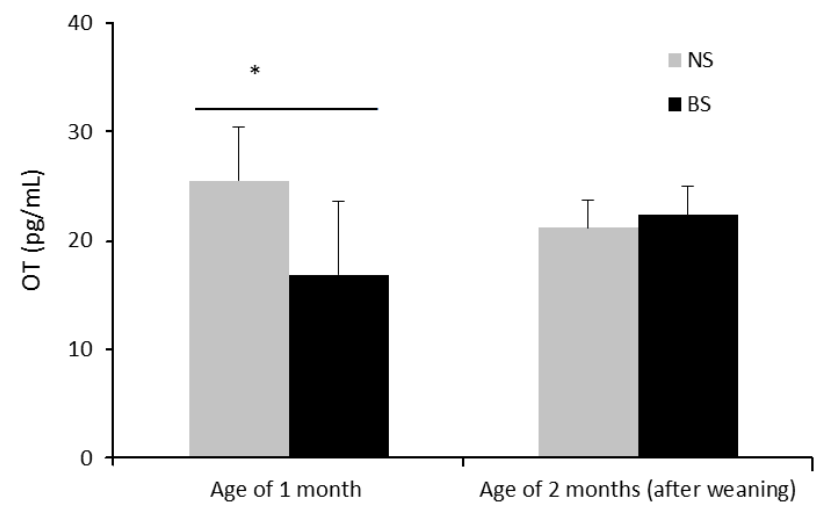

Figure 1. Serum oxytocin (OT) concentrations in natural suckling and bucket-suckling calves. ${ }^{*}$ Statistical difference between the natural suckling and bucket-suckling treatments $(\mathrm{p}=0.05)$. NS, natural-suckling group; BS, bucket-suckling group. 
Effects of the suckling system on serum cortisol concentration

Serum cortisol concentrations (mean $\pm \mathrm{SD}, \mathrm{ng} / \mathrm{mL}$ ) of NS calves were $5.8 \pm 2.5$ and $9.0 \pm 2.8$ at the age of 1 month and 2 months, respectively, while those of $\mathrm{BS}$ calves were $10.0 \pm 2.8$ and $10.4 \pm 5.2$, respectively. At the age of 1 month, mean cortisol concentration of NS was significantly lower than that of BS $(p<0.05)$, whereas at the age of 2 months, the mean concentration of NS reached the level of BS (Figure 2).

Additionally, OT concentration was negatively correlated with the serum cortisol concentration in 1-month-old calves $(\mathrm{r}=-0.61, \mathrm{p}=0.06)$.

Effects of the suckling system and serum oxytocin concentration on behaviors in the open-field arena

The duration of time calves spent near the decoy was significantly affected by the suckling system; NS calves lingered near the decoy longer than BS calves $(p<0.05)$ (Table 1). The bouts of approaches to the decoy were affected by both the suckling system and serum OT concentration ( $\mathrm{p}<0.01$ for both variables) (Table 1$)$. It was lower in the natural- compared with the bucket-suckling system, and increased with serum OT concentration. The bouts of explorations in the open-field arena increased with serum OT concentration $(p=0.06)$. The duration of contact with the net cage and the occurrence of self-grooming behavior were not affected by either the rearing system or serum OT concentration (Table 1).

\section{DISCUSSION}

Serum oxytocin concentration in the natural-suckling group

It was reported that serum OT concentrations were instantaneously higher in calves during suckling that lasted only for 1 minute (Lupoli et al., 2001), however, the suckling effect on basal OT concentration was unclear. Long-term rearing environments have been suggested to cause physiological changes in some animal species and humans. It was shown that in children exposed to long-term low-frequency noise during the night, free cortisol secretion

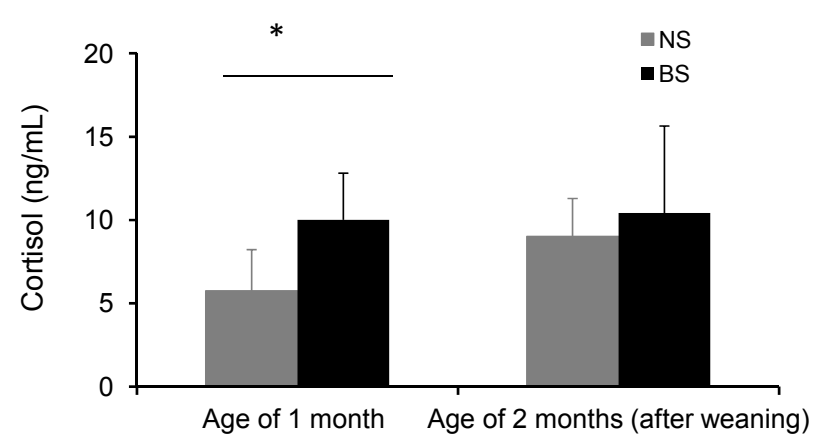

Figure 2. Serum cortisol concentrations in natural suckling and bucket-suckling calves. * Statistical difference between the natural suckling and bucket-suckling treatments $(\mathrm{p}<0.05)$. NS, naturalsuckling group; BS, bucket-suckling group.

chronically increased in the first half of the night and cortisol circadian rhythms were seriously disturbed (Ising and Ising, 2002). In the present study, we revealed that the natural suckling system elevated the baseline of serum OT in 1-month-old calves. There is also a possibility that basal serum OT is higher in the NS 2-months-old group than in $\mathrm{BS}$ at the time of the open-field test.

NS calves were raised with their dams and in the company with other cows and their calves, and calves were allowed to suckle freely every day. Neumann et al. (1994) reported the positive feedback action of OT in the supraoptic nucleus during suckling, suggesting that the positive feedback of natural suckling may increase basal serum OT concentrations. In addition, there seems to be another possibility for increasing basal serum OT concentrations. Firstly, one of the possibilities for higher OT concentrations in NS calves than in BS calves may be the presence of their dams. Wood-Gush et al. (1984) reported higher frequency of interactions of calves with their dams until 4 weeks of age $(0.72 / 30 \mathrm{~min})$ than with other cows $(0.18 / 30 \mathrm{~min})$ and calves $(0.68 / 30 \mathrm{~min})$. It is indicated that interactions with dams seems to be more important than interactions with pen mates in the first few weeks of life. In particular, maternal licking is important as it stimulate calf activity (Metz and Metz, 1986) and drying of the calf's coat to reduce evaporative heat loss (Edwards and Broom, 1982) and decrease bacteria (Kohari et al.,

Table 1. The behaviors of calves in the open-field with the Holstein calf decoy during the 20 minutes of observation

\begin{tabular}{|c|c|c|c|c|}
\hline \multirow{2}{*}{ Ethogram } & \multicolumn{2}{|c|}{ Type of rearing } & \multirow{2}{*}{$\begin{array}{c}\text { Effect of rearing } \\
\text { system }\end{array}$} & \multirow{2}{*}{ Effect of serum OT } \\
\hline & Natural suckling & Bucket-suckling & & \\
\hline Duration of contact with the net cage $(\mathrm{s})^{\mathrm{a}}$ & $100.2 \pm 57.1$ & $33.2 \pm 26.4$ & NS & NS \\
\hline Duration of staying near the decoy (s) & $682.5 \pm 258.5$ & $192.8 \pm 112.9$ & $\mathrm{p}<0.05$ & NS \\
\hline Bouts of approaches to the decoy & $3.6 \pm 2.4$ & $4.4 \pm 2.9$ & $\mathrm{p}<0.01$ & $\mathrm{p}<0.01$ \\
\hline Bouts of explorations in the open-field arena & $11.2 \pm 3.9$ & $10 \pm 2.9$ & NS & $\mathrm{p}=0.06$ \\
\hline Bouts of self-grooming behavior & $7.6 \pm 4.6$ & $5.6 \pm 7.6$ & NS & NS \\
\hline
\end{tabular}

OT, oxytocin; NS, not significant; SD, standard deviation.

Values are presented as mean \pm SD.

${ }^{a}$ The calf decoy was present in the net cage. 
2009). These positive interactions may stimulate OT secretion according to Odendaal and Meintjes (2003). Additionally, we confirmed that time spent on being allogroomed is positively correlated with serum OT concentration in cows in our personal observation, and manual brushing stimulated serum OT concentration in cows in our previous study (Chen et al., 2014). Hence, maternal interactions with cows may have similar effects as allo-grooming and manual brushing on serum OT concentration of calves. Secondly, the interactions of calves with peers, especially play, may be also important. Though our knowledge of play is still in its infancy, play is most often associalted with a stress-free environment and it is suggested that engaging in play can reduce stress (Mills, 2010). Bredewold et al. (2014) reported that OT receptor antagonists showed less social play in rats, which means OT modulates social behavior. Therefore, higher serum OT concentrations from frequent contact, allo-grooming and play with dams and peers in NS calves may relate to the increase of basal serum OT concentration.

\section{Serum cortisol concentration in bucket-suckling calves}

As mentioned in the introduction, the bucket-suckling rearing system may induce behavioral, psychological, and physiological problems in calves. Bucket suckling may be one of the stressors resulting in higher serum cortisol concentrations. The present study showed that serum cortisol concentration was higher in BS than NS calves.

It was shown that mother-reared monkeys exhibited more social contact and less abnormal repetitive behaviors, and had depressed plasma cortisol concentrations compared with nursery-reared ones (Winslow et al., 2003). Further, they indicated that rearing conditions have long-term effects on both social behavior and central OT concentrations. Further, according to Neumann et al. (1994) that OT released within the supraoptic nucleus area during suckling modulates the release of OT into the bloodstream. We speculated that the increase of serum OT concentration via natural suckling for 2 months and contacts with dams and peers might be related to the suppression of serum cortisol secretion. In the present study, we found that the serum OT and cortisol concentrations in 1-month-old calves were negatively correlated. It might be supported with the reports that intracerebroventricularly injected OT attenuated the cortisol response to isolation in Holstein steers, and lowered cortisol levels in rats (Petersson et al., 1996; Uvnäs-Moberg et al., 1998; Yayou et al., 2008). Our results suggest that serum OT concentration may correlate with cortisol concentration in cattle.

In the present study, significant differences of both OT and cortisol concentrations between NS and BS calves disappeared one week after weaning. This is possibly caused by different weaning stressors between them. The
NS calves were raised with their dams until weaning and they hardly fed on the solid food, although it was offered at the same amount as that given to the BS calves from 1 month. Therefore, starvation by weaning might be more severe in NS calves than in BS calves. Additionally, their weaning stressors might include starvation with the halting of milk feeding, and loneliness with the breaking of the mother-infant psychological and physiological relationship (Veissier and Le Neindre, 1989). However, in BS calves, also weaned at 2 months, weaning stressors might be lower because they been independent from birth, and the interruption of the milk feed might not introduce starvation, since BS calves were able to consume a solid starter diet of about $1 \mathrm{~kg} / \mathrm{d}$ even in the suckling period.

However, weaning stressors may only have short-term effects on physiological changes. It was reported that weaning increased acute-phase proteins such as ceruloplasmin, which peaked 7 days post-weaning in steers (Arthington et al., 2005). In the present study, the effect of weaning stressors on serum OT and cortisol concentrations might last 7 days or longer, but thereafter, the physiological parameters might return to the pre-weaning values. Since the open-field test was conducted 2-weeks post-weaning, we thought it is possible to use the 1-month-old serum OT and cortisol concentrations as the basal data to clarify the responses from the open-field test.

\section{Effects of the rearing system and serum oxytocin concentration on affiliative and investigative behaviors to the novel stimuli}

We found that the duration of staying near the decoy, not the numbers of approaches to the decoy, was higher in NS than in BS calves. The NS calves were affiliative to novel materials, concurring with the report that calves showed more play (Jensen et al., 1997) and social behavior (Babu et al., 2004) reared in groups than in individual pens. Wagner et al. (2013) also reported that mothers rearing calves initiated more frequent social play than artificially reared calves.

It was reported that OT might induce affiliative behavior in rats (Babygirija et al., 2012) and voles (Rose et al., 2009). In the present study, we found that the bouts of approaches to the decoy were affected by serum OT concentration, showing that calves with higher serum OT concentrations approached the decoy more often. Furthermore, the bouts of explorations in the open-field arena were similarly affected by serum OT concentrations, where there was a positive correlation between serum OT concentration and the number of explorations in the novel environment. The principal component analysis carried out by Yayou et al. (2010) indicated that in unsocial contexts, the basal serum OT concentration of calves was negatively related to curiosity, and tended to have a positive 
relationship with fearfulness in novel environments. However, they did not analyze the relationship between OT concentration and exploratory behavior, and exploratory behavior was not correlated with the principal components of curiosity and fearfulness. The results of the present study showed that the serum OT concentration, and not natural suckling, seems to be correlated with exploratory behavior rather than affiliative behavior.

In summary, we showed that natural suckling for 2 months and interactions with their dams and peers elevates the base level of serum OT concentration in calves. Additionally, serum OT concentration may be negatively correlated with cortisol concentration, and positively correlated with exploratory behavior in novel environments. Thus, OT is a good indicator of animal welfare, and studies on animal welfare should focus on how to increase comfort, alleviate stress, and increase stress tolerance, and not only determine when stress occurs in farm animals.

\section{CONFLICT OF INTEREST}

We certify that there is no conflict of interest with any financial organization regarding the material discussed in the manuscript.

\section{ACKNOWLEDGMENTS}

This study was supported by the Laboratory of Land Ecology, Graduate School of Agricultural Science, Tohoku University. We also specially thank Mr. Yuuki Arino, Mr. Takashi Chiba, and Mr. Shibuya from the Field Science Center for their supporting, and Megmilk Snow Brand Co., Ltd., Osaki, Miyagi, for supplying the decoy.

\section{REFERENCES}

Arthington, J. D., J. W. Spears, and D. C. Miller. 2005. The effect of early weaning on feedlot performance and measures of stress in beef calves. J. Anim. Sci. 83:933-939.

Babu, L. K., H. N. Pandey, and A. Sahoo. 2004. Effect of individual versus group rearing on ethological and physiological responses of crossbred calves. Appl. Anim. Behav. Sci. 87:177-191.

Babygirija, R., D. Cerjak, S. Yoshimoto, I. Gribovskaja-Rupp, M. Bülbül, K. Ludwig, and T. Takahashi. 2012. Affiliative behavior attenuates stress responses of GI tract via upregulating hypothalamic oxytocin expression. Auton. Neurosci. 169:28-33.

Bredewold, R., C. J. W. Smith, K. M. Dumais, and A. H. Veenema. 2014. Sex-specific modulation of juvenile social play behavior by vasopressin and oxytocin depends on social context. Front. Behav. Neurosci. 8:216.

Broom, D. M. and A. F. Fraser. 2007. Domestic Animal Behaviour and Welfare. 4th edn. Cambridge University Press, London, UK.
Chen, S., S. Tanak, S. Roh, and S. Sato. 2014. Factors affecting oxytocin concentration and relationship between oxytocin concentration and affiliative behavior. In: Proceedings of the 48th International Congress of the International Society for Applied Ethology. Vitoria-Gasteiz, Spain. p. 137.

Das, S. M., I. Redbo, and H. Wiktorsson. 2000. Effect of age of calf on suckling behaviour and other behavioural activities of Zebu and crossbred calves during restricted suckling periods. Appl. Anim. Behav. Sci. 67:47-57.

Edwards, S. A. and D. M. Broom. 1982. Behavioural interactions of dairy cows with their newborn calves and the effects of parity. Anim. Behav. 30:525-535.

Grøndahl, A. M., E. M. Skancke, C. M. Mejdell, and J. H. Jansen. 2007. Growth rate, health and welfare in a dairy herd with natural suckling until 6-8 weeks of age: a case report. Acta Vet. Scand. 49:16.

Ising, H. and M. Ising. 2002. Chronic cortisol increases in the first half of the night caused by road traffic noise. Noise Health 4:13-21.

Hernández, C., A. Orihuela, S. Fröberg, and L. M. Lidfors. 2006. Effect of restricted suckling on physiological and behavioural stress parameters in dual-purpose cattle in the tropics. Livest. Sci. 99:21-27.

Jensen, M. B., K. S. Vestergaard, C. C. Krohn, and L. Munksgaard. 1997. Effect of single versus group housing and space allowance on responses of calves during open-field tests. Appl. Anim. Behav. Sci. 54:109-121.

Krohn, C. C., J. Foldager, and L. Mogensen. 1999. Long-term effect of colostrum feeding methods on behaviour in female dairy calves. Acta Agric. Scand. Anim. Sci. 49:57-64.

Krohn, C. C. 2001. Effects of different suckling systems on milk production, udder health, reproduction, calf growth and some behavioural aspects in high producing dairy cows: A review. Appl. Anim. Behav. Sci. 72:271-280.

Kirsch, P., C. Esslinger., Q. Chen, D. Mier, S. Lis, S. Siddhanti, H. Gruppe, V. S. Mattay, B. Gallhofer, and A. Meyer-Lindenberg. 2005. Oxytocin modulates neural circuitry for social cognition and fear in humans. J. Neurosci. 25:11489-11493.

Kohari, D., S. Sato, and Y. Nakai. 2009. Does the maternal grooming of cattle clean bacteria from the coat of calves? Behav. Processes 80:202-204.

Lupoli, B., B. Johansson, K. Uvnäs-Moberg, and K. SvennerstenSjaunja. 2001. Effect of suckling on the release of oxytocin, prolactin, cortisol, gastrin, cholecystokinin, somatostatin and insulin in dairy cows and their calves. J. Dairy Res. 68:175187.

Metz, J. and J. H. M. Metz. 1986. Maternal influence on defecation and urination in the newborn calf. Appl. Anim. Behav. Sci. 16:325-333.

Mills, D. S. 2010. The Encyclopedia of Applied Animal Behaviour and Welfare. CABI, Wallingford, UK.

National Agriculture and Food Research Organization. 2008. Japanese Feeding Standard for Beef Cattle. Japan Livestock Industry Association, Tokyo, Japan.

Neumann, I., E. Koehler, R. Landgraf, and J. Summy-Long. 1994. An oxytocin receptor antagonist infused into the supraoptic nucleus attenuates intranuclear and peripheral release of oxytocin during suckling in conscious rats. Endocrinology 134:141-148. 
Nowak, R., T. M. Murphy, D. R. Lindsay, P. Alster, R. Andersson, and K. Uvnäs-Moberg. 1997. Development of a preferential relationship with the mother by the newborn lamb: importance of the sucking activity. Physiol. Behav. 62:681-688.

Odendaal, J. S. J. and R. A. Meintjes. 2003. Neurophysiological correlates of affiliative behaviour between humans and dogs. Vet. J. 165:296-301.

Petersson, M., P. Alster, T. Lundeberg, and K. Uvnäs-Moberg. 1996. Oxytocin increases nociceptive thresholds in a long-term perspective in female and male rats. Neurosci. Lett. 212:87-90.

Rose, H. E., C. D. Cole, Y. Smith, I. D. Neumann, R. Landgraf, A. Z. Murphy, and L. J. Young. 2009. Characterization of the oxytocin system regulating affiliative behavior in female prairie voles. Neuroscience 162:892-903.

Sato, S., R. Nagamine, and T. Kubo. 1994. Tongue-playing in tethered Japanese Black cattle: diurnal patterns, analysis of variance and behaviour sequences. Appl. Anim. Behav. Sci. 39:39-47.

Seo, T., S. Sato, K. Kosaka, N. Sakamoto, K. Tokumoto, and K. Katoh. 1998. Development of tongue-playing in artificially reared calves: effects of offering a dummy-teat, feeding of short cut hay and housing system. Appl. Anim. Behav. Sci. $56: 1-12$.

Suárez, M. M., M. A. Rivarola, S. M. Molina, N. I. Perassi, G. M. Levin, and R. Cabrera. 2001. Periodic maternal deprivation and lesion of anterodorsal thalami nuclei induce alteration on hypophyso adrenal system activity in adult rats. Life Sci. 69:803-813.
Svanidze, M. D., N. G. Bukiya, and M. P. Butskhrikidze. 2012. Effect of oxytocin on the emotional state and behavior of rats under stress conditions. Neurophysiology 43:365-368.

Uvnäs-Moberg, K., P. Alster, M. Petersson, A. Sohlström, and E. Björkstrand. 1998. Postnatal oxytocin injections cause sustained weight gain and increased nociceptive thresholds in male and female rats. Pediatr. Res. 43:344-348.

Veissier, I. and P. Le Neindre. 1989. Weaning in calves: its effects on social organization. Appl. Anim. Behav. Sci. 24:43-54.

Wagner, K., K. Barth, E. Hillmann, R. Palme, A. Futschik, and A. Waiblinger. 2013. Mother rearing of dairy calves: Reactions to isolation and to confrontation with an unfamiliar conspecific in a new environment. Appl. Anim. Behav. Sci. 147:43-54.

Winslow, J. T., P. L. Noble, C. K. Lyons, S. M. Sterk, and T. R. Insel. 2003. Rearing effects on cerebrospinal fluid oxytocin concentration and social buffering in rhesus monkeys. Neuropsychopharmacology 28:910-918.

Wood-Gush, D. G. M., K. Hunt, K. Carson, and S. G. C. Dennison. 1984. The early behaviour of suckler calves in the field. Biol. Behav. 9:295-306.

Yayou, K., S. Ito, E. Kasuya, M. Sutoh, S. Ohkura, and H. Okamura. 2008. Intracerebroventricularly administered oxytocin attenuated cortisol secretion, but not behavioral responses, during isolation in Holstein steers. J. Vet. Med. Sci. 70:665-671.

Yayou, K., S. Ito, N. Yamamoto, S. Kitagawa, and H. Okamura. 2010. Relationships of stress responses with plasma oxytocin and prolactin in heifer calves. Physiol. Behav. 99:362-369. 